The Spectrum of

\title{
Award-Winning Etching Process Cuts Solar Cell Costs
}

In general, when it comes to photovoltaic (PV) solar cells, the higher their efficiency, the higher their price tag. To increase cell efficiencies while lowering costs, scientists at the National Renewable Energy Laboratory (NREL) invented the "black silicon" nanocatalytic wet-chemical etch. This inexpensive, one-step method enables the creation of high-efficiency crystalline silicon solar cells based on an innovative antireflection approach that promises to significantly reduce manufacturing costs.

Most of today's solar cells are made from silicon, and NREL's simple antireflection etch turns silicon wafers black, allowing them to absorb more than $98 \%$ of incident sunlight. NREL's new process, a one-step immersion in a chemical bath, creates a highly antireflective layer on the surface of the wafers at a cost of just a few cents per watt-potentially replacing pricey antireflective solar cell coatings and lowering the cost of crystalline silicon devices. NREL's innovative approach to cutting the cost of silicon solar cell antireflection produced a black silicon cell with a validated $16.8 \%$ conversion efficiency. R\&D Magazine awarded the technology an R\&D 100 Award in 2010, identifying it as one of the top 100 technological innovations of the year.

\section{Wasting Less Sunlight-and Less Capital}

Solar cells convert sunlight into electricity, and any photons reflected from the cell surface are wasted. Manufacturers have devised ways to boost the amount of light absorbed by silicon solar cells, including chemically etching the surface on the micrometer scale and then depositing a thin antireflective layer with a carefully controlled thickness. Unfortunately, the equipment and processes for these conventional methods add significant cost to the solar cell and often require the use of environmentally harmful gases. And even when both techniques are used, cells still reflect a significant amount of the sun's spectrum, absorbing only 93\%-97\% of the sunlight they receive.

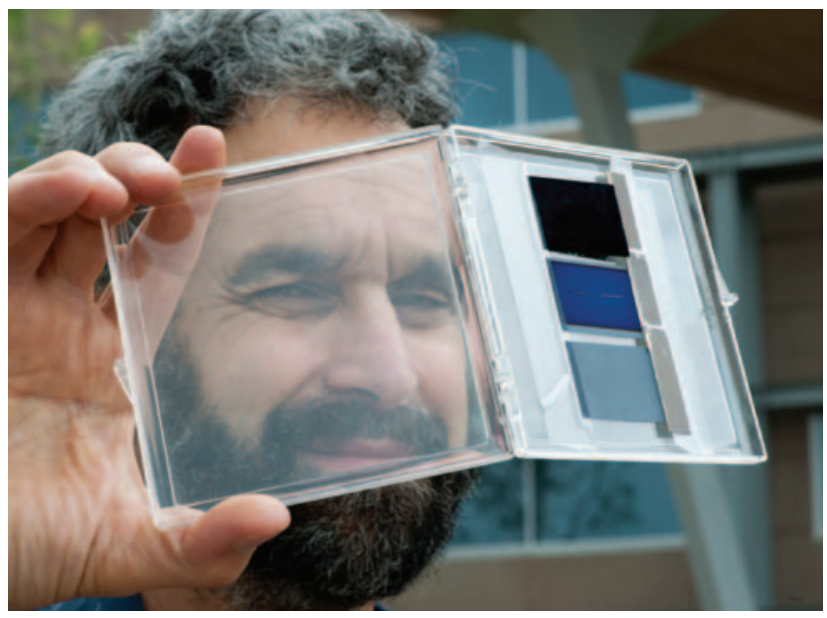

NREL Principal Scientist Howard Branz examines silicon wafers with various antireflective treatments. The cells use the NREL black silicon method (top), a conventional antireflective coating with texturing (center), and the conventional texturing method only (bottom). Photo by Dennis Schroeder, NREL/PIX 17744

Clean Energy Innovation

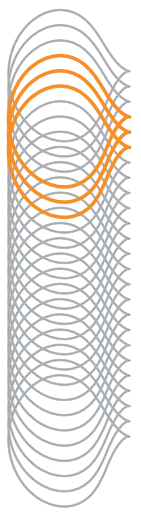

Fundamental Science

Market-Relevant Research

Systems Integration

Testing and Validation

Commercialization

Deployment

Through deep technical expertise and an unmatched breadth of capabilities, NREL leads an integrated approach across the spectrum of renewable energy innovation. From scientific discovery to accelerating market deployment, NREL works in partnership with private industry to drive the transformation of our nation's energy systems.

This case study illustrates NREL's innovations in MarketRelevant Research.

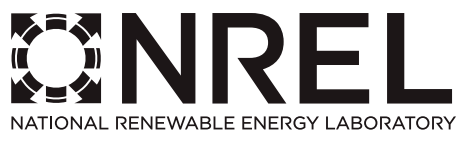

NREL is a national laboratory of the U.S. Department of Energy, Office of Energy Efficiency and Renewable Energy, operated by the Alliance for Sustainable Energy, LLC. 
NREL's researchers believed that a better — and less expensive-result could be obtained by applying a completely different antireflection principle: an etching process known as black silicon. Although such processes had been experimented with in the past, the NREL team developed a better, faster etching process that could easily be integrated into existing manufacturing lines. NREL's black silicon etch process produces higher-efficiency solar cells because less light is wasted-less than $2 \%$ of the solar spectrum, or about three times less than more costly antireflection techniques.

\section{Tiny Holes, Big Absorbency Gains}

To etch the silicon, a wafer is immersed in a solution of hydrogen peroxide, hydrofluoric acid, and a small amount of chloroauric acid, which is composed of hydrogen, chlorine, and gold. Tiny nanoparticles of gold instantly form and act as a catalyst for chemical reactions, producing a nanometer-scale porous surface on the cell wafer. The nanoscale pores - on the order of a billionth of a meter in diameter-are much smaller than the wavelength of the incident light, so they suppress reflection across the full spectrum of sunlight.

As the tiny holes deepen, they make the metallic gray silicon appear increasingly dark until it becomes almost pure black, absorbing nearly all frequencies of sunlight. The surface becomes riddled with minute pores of varying depths with no sharp interfaces that would reflect light, creating a highly absorbent silicon wafer.

At room temperature, NREL's black silicon etching process takes about three minutes, and at $100^{\circ} \mathrm{F}$, the process takes less than a minute. In contrast, the etching process that prepares silicon wafers for conventional antireflective coatings takes 8-30 minutes, and applying the coatings adds even more processing time.

\section{Increased Efficiency, Simplified Production, and Reduced Cost}

Monocrystalline solar cells treated with the NREL black silicon etch process exhibit a conversion efficiency of $16.8 \%$ - about the same efficiency as a typical crystalline silicon cell with a more costly antireflective coating. Previous black silicon approaches achieved efficiencies of $13.9 \%$ at best. The NREL team has also produced a 16.2\%efficient black silicon cell using a less-expensive multicrystalline silicon wafer.

As a replacement for conventional antireflective coatings, NREL's black silicon could reduce the cost of energy delivered over the life of a silicon PV array by $2 \%$ or $3 \%$ significant gains in the PV world, a "game of inches" in which even half a percentage point is noteworthy. Plus, the NREL method actually simplifies solar cell processing, speeds throughput, uses less costly machinery, and produces fewer harmful byproducts than conventional antireflection techniques.

PV manufacturers purchased more than $\$ 4$ billion in equipment in 2008, and they seek every possible cost and efficiency advantage over their competitors. NREL estimates that its method can reduce processing costs by 4\%-8\%, resulting in overall savings in solar cell manufacturing of 1\%-3\%, making black silicon particularly appealing.

The NREL team continues to seek further improvements to the process. The team is working to produce cells with efficiencies greater than 19\% by reducing reflection and improving the conversion efficiency for blue light.

\section{Black Silicon by the Numbers}

NREL's innovative etch boasts numerous cost and performance benefits which, taken together, could reduce the levelized cost of energy from a silicon PV array by about $2.5 \%$.

- Reduced capital costs and better environmental safety. Assuming equivalent cell efficiencies, NREL's black silicon will reduce capital costs by $16 \%$ while also reducing operating expenses and eliminating environmentally harmful gases. This capital cost reduction lowers the barrier to PV plant expansion and could speed PV deployment.

- Reduced module cost. NREL's etch also provides a direct reduction of module cost of $\$ 0.02$ to $\$ 0.04$ per watt of delivered module power-or $\$ 4$ to $\$ 8$ off the cost of a typical 200-watt solar module.

- Improved cell efficiency. Increases in manufactured cell efficiencies of up to $0.8 \%$ are possible because of the reduced reflectance of black silicon. This would reduce silicon PV module costs by an additional $\$ 20$ per module.

-Versatile range in incident light angle. The superior angle-of-incidence performance of black silicon may result in solar modules that produce $1 \%-3 \%$ more energy because of better performance in the morning and evening and under diffuse-light conditions.

- Reduced balance-of-system costs. Increasing the efficiency and energy production of PV modules will reduce some balance-of-system costs. Fewer modules mean fewer racks and lower installation costs.

\section{National Renewable Energy Laboratory}

1617 Cole Boulevard Golden, Colorado 80401 303-275-3000 • www.nrel.gov

NREL is a national laboratory of the U.S. Department of Energy, Office of Energy Efficiency and Renewable Energy, operated by the Alliance for Sustainable Energy, LLC.

NREL/FS-6A42-50063 • Revised May 2011

Printed with a renewable-source ink on paper containing at least $50 \%$ wastepaper, including $10 \%$ post consumer waste. 